\title{
Multiple Peritoneal Inclusion Cysts Mimicking an Ovarian Tumour - A Rare Case Report
}

\author{
Reetu Yadav ${ }^{1}$, Preeti Singh ${ }^{2}$ \\ ${ }^{1}$ Department of Obstetrics and Gynaecology, MAMC, Delhi, India. \\ 2Department of Obstetrics and Gynaecology, MAMC, Delhi, India.
}

\section{INTRODUCTION}

Peritoneal inclusion cysts (PIC) are uncommon abdominopelvic cysts seen in perimenopausal women. It is often misdiagnosed clinically as an ovarian tumour due to similar presentation and mimicking findings on radiology. We describe a perimenopausal woman presenting with pelvic mass. Her clinical finding on radiology suggested an ovarian tumour; however, biopsy revealed it to be a case of peritoneal inclusion cysts.

\section{PRESENTATION OF CASE}

A 35-year-old female P1L1 was admitted with complaints of distention of abdomen since 8 months, pain in lower abdomen on and off since 8 months, history of cholecystectomy in 2007 and history of bilateral cystectomy in 2012. Histopathology specimen was AFB positive ATT was taken for 6 months. On examination, abdomen was distended, multiple masses felt- $10 \times 10 \mathrm{~cm}$ on right side, $12 \times 10 \mathrm{~cm}$ on left side and $4 \times 3 \mathrm{~cm}$ mass in lower abdomen. On P/V examination uterus could'nt be made out, on P/R rectal mucosa free, no nodularity felt in POD. On Investigation- CA125: 13.9, CEA 0.9, B HCG 0.1. On ultrasound pelvis uterus anteverted, normal echotexture and morphology, ET $9 \mathrm{~mm}$, evidence of tubular cystic lesion in right adnexa $8.3 \times 7.8$ $\mathrm{cm}$ with incomplete septae and internal echoes within. Similar lesion in left adnexa $6 \times 8 \mathrm{~cm}$ ? bilateral hydrosalpinx. CECT Pelvis two large abdominopelvic cystic lesion both cystic lesion seem to communicate with each other $1^{\text {st }}$ masses contouring the shape of peritoneal cavity encasing the right vary with few enhancing septation with in $18 \times 14 \times 11 \mathrm{~cm}$, partially encasing the uterus and left ovary posteriorly in the inferior aspect, it is abutting the rectum and rectosigmoid junction, $2^{\text {nd }}$ large cystic lesion $21.8 \times 20 \times 10 \mathrm{~cm}$ overlying it hypochondrium, lumber and iliac fossa, left ovary shows few cystic component largest $4.3 \times 2.8 \mathrm{~cm}$. Uterus normal size. No enlarged lymph nodes seen. On ascitic fluid cytology $80 \%$ lymphocyte, $20 \%$ polymorph, sugar $55 \mathrm{mg} / \mathrm{dL}, 7.2 \mathrm{mg} / \mathrm{dL}$, CB NAAT Neg, on cytology: few lymphocyte and degenerated cells in background of proteinaceous material. On FNAC: acellular proteinaceous material seen, negative for AFB. Plan for surgery taken, Exploratory laparotomy followed by aspiration of cyst and partial cyst wall excision. On per operative finding: rt side $25 \times 20 \mathrm{~cm}$ cysti mass, left side cyst on upper side $15 \times 10 \mathrm{~cm}$ and lower side $20 \times 15 \mathrm{~cm}$ cyst in which uterus with bilateral tubes and ovary encased, bowel densely adhered with cyst, small cyst $8 \times 6 \mathrm{~cm}$ seen behind the left cystic mass, bilateral tubes and ovary normal, aspiration of all cyst done and cyst wall excision done partially in view of densely adhered bowel. Cyst wall send for histopathology suggestive of Peritoneal Inclusion Cyst with chronic inflammation.
Corresponding Author:

Reetu Yadav,

D/o. Lalan Prasad Yadav,

Bauripara, Near Alka Industries,

Ambikapur, Chhattisgarh, India

E-mail: reetuyadav.24@gmail.com

DOI: $10.14260 / j e m d s / 2019 / 843$

Financial or Other Competing Interests: None.

How to Cite This Article:

Yadav R, Singh P. Multiple peritoneal inclusion Cysts mimicking an ovarian tumour- a rare case report. J. Evolution Med. Dent. Sci. 2019;8(51):3893-3895, DOI: 10.14260/jemds/2019/843

Submission 28-08-2019, Peer Review 03-12-2019, Acceptance 10-12-2019, Published 23-12-2019. 

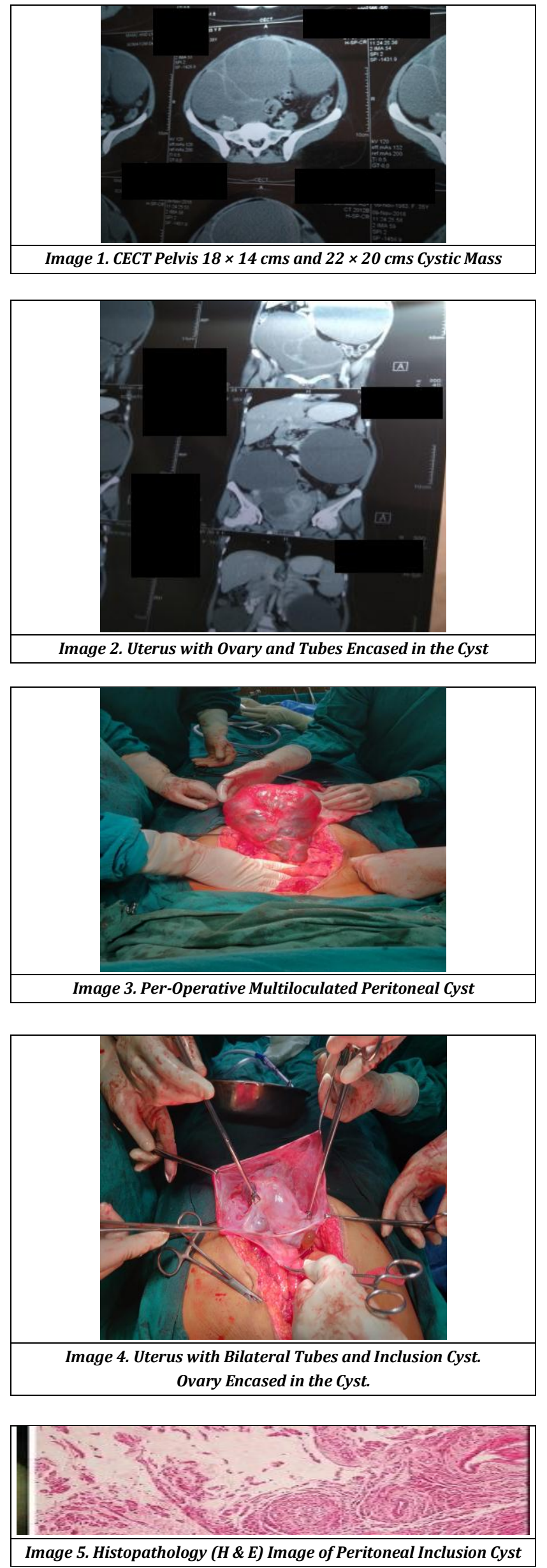

\section{DISCUSSION}

PIC, also called benign cystic peritoneal mesothelioma, inflammatory cysts of the peritoneum, postoperative peritoneal cyst, benign papillary peritoneal cystosis, are mesothelium-lined cysts classically presenting in perimenopausal woman and are diagnostic dilemmas for gynaecologists and radiologists.[1,2,3,4,5] Usual presentation is progressive abdominal or pelvic pain or palpable mass as present in our patient. Rarely there can be backache, dyspareunia, constipation, tenesmus, urinary frequency or incontinence, anorexia, dysfunctional uterine bleeding, or infertility. Pulmonary embolism and venous stasis may also occur secondary to compression. Risk factors include previous intraperitoneal surgeries performed 6 months to 20 years earlier by any route, intraperitoneal inflammation, pelvic inflammatory disease, peritoneal tuberculosis, leiomyoma, tubo-ovarian abscess, etc. Our patient had tubal ligation, leiomyoma and pelvic inflammatory disease.

PIC may be misdiagnosed as mucinous cystadenoma of ovaries for similar presentation and slightly raised CA125 derived from coelomic epithelium in both conditions. USG features are non-specific, with smooth thin walled multiseptated cysts containing liquid of different attenuation. ${ }^{22}$ CT scan similarly give cobweb appearance of loculated fluid with septations within, conforming to the peritoneal space with ipsilateral ovary within it or in the wall. Intraoperative PIC typically presents as confluent mass or discontinuous cysts studded together. Unaware of the entity, we only entertained the differential diagnosis of hydatid cyst. Postulated pathology for PIC includes inability to absorb physiological secretions of active ovaries by diseased, inflamed or fibrosed peritoneum forming cysts within peritoneal adhesions.[3] We missed the diagnosis of this uncommon entity possibly because of similar age, symptoms, signs and USG features mimicking benign mucinous cystadenoma of ovary.

Management varies from observation with serial imaging, hormones, image-guided aspiration with or without sclerotherapy, and surgical excision to complete resection. ${ }^{[3]}$ Hormones include oral contraceptives, tamoxifen, leuprolide, etc. Aspiration with oral contraceptive combination gives good result. USG /fluoroscopy-guided sclerotherapy with 10\% iodine or absolute ethanol reported $90 \%$ success rate. The gold standard treatment is complete resection laparoscopically or by laparotomy. However, recurrence may occur in up to $50 \%$ of cases.

\section{CONCLUSIONS}

PIC consciousness particularly in patients with predisposing conditions may help suspect and diagnose this uncommon entity. This may permit conservative management in selected cases with close follow-up for possible recurrence. 


\section{REFERENCES}

[1] Villerie AM, Lerner JP, Wright JD, et al. Peritoneal inclusion cysts: a review. Obstet Gynecol Surv 2009;64(5):321-34.

[2] Veldhius WB, Akiin O, Goldman D, et al. Peritoneal inclusion cysts: clinical characteristics and imaging features. Eur Radiol 2013;23(4):1167-74.
[3] Lee SW, Lee SJ, Jang DG, et al. Comparison of laparoscopic and laparotomic surgery for the treatment of peritoneal inclusion cyst. Int J Med Sci 2012;9(1):14-9.

[4] Guerriero S, Ajossa S, Mais V, et al. Role of transvaginal sonography in the diagnosis of peritoneal inclusion cysts. J Ultrasound Med 2004;23(9):1193-200.

[5] Jeong JY, Kim SH. Sclerotherapy of peritoneal inclusion cysts: preliminary results of seven patients. Korean J Radiol 2001;2(3):164-70. 